\title{
Quality of life and metabolic status in mildly depressed women with type 2 diabetes treated with paroxetine: $A$ single-blind randomised placebo controlled trial
}

\author{
Maria Paile-Hyvärinen ${ }^{1,2}$, Kristian Wahlbeck*3,4 and Johan G Eriksson ${ }^{2}$
}

Address: ${ }^{1}$ Department of Psychiatry, University of Helsinki, Lapinlahti Hospital, P.O.Box 320, FIN-00029 HUCH, Helsinki, Finland, ${ }^{2}$ National Public Health Institute, Mannerheimintie 166, FIN-00300 Helsinki, Finland, ${ }^{3}$ National Research and Development Centre for Welfare and Health (STAKES), P.O.Box 220, FIN-00531 Helsinki, Finland and ${ }^{4}$ Vaasa Central Hospital, Vaasa, Finland

Email: Maria Paile-Hyvärinen - maria.paile@helsinki.fi; Kristian Wahlbeck* - kristian.wahlbeck@stakes.fi;

Johan G Eriksson - johan.eriksson@ktl.fi

* Corresponding author

Published: I4 May 2003

BMC Family Practice 2003, 4:7
Received: 9 January 2003

Accepted: 14 May 2003

This article is available from: http://www.biomedcentral.com/I47I-2296/4/7

(c) 2003 Paile-Hyvärinen et al; licensee BioMed Central Ltd. This is an Open Access article: verbatim copying and redistribution of this article are permitted in all media for any purpose, provided this notice is preserved along with the article's original URL.

\begin{abstract}
Background: Depression is prevalent in people with type 2 diabetes and affects both glycemic control and overall quality of life. The aim of this trial was to evaluate the effect of the antidepressant paroxetine on metabolic control, quality of life and mental well-being in mildly depressed women with type 2 diabetes.
\end{abstract}

Methods: We randomised 15 mildly depressed women with non-optimally controlled type 2 diabetes to a 10 -week single-blind treatment with either paroxetine $20 \mathrm{mg}$ per day or placebo. Primary efficacy measurements were glycemic control and quality of life. Glycosylated hemoglobin $A_{I c}\left(G H b A_{l c}\right)$ was used as a measure of glycemic control. Quality of life was evaluated using RAND36. Mental state was assessed using two clinician-rated scoring instruments, Hamilton's Anxiety Scale (HAM-A) and Montgomery-Åsberg's Depression Rating Scale (MADRS), and a patient-rated scoring instrument, Beck's Depression Inventory (BDI).

Results: At the end of the study no significant difference between groups in improvement of quality of life was found. $A$ trend towards a superior improvement in glycemic control was found in the paroxetine group $(p=0.08)$. A superior increase in sex-hormone-binding-globuline (SHBG) levels was evidenced in the paroxetine group $(p=0.01)$ as a sign of improved insulin sensitivity. There was also a trend for superior efficacy of paroxetine in investigator-rated anxiety and depression. This notion was supported by a trend for superior decrease of serum cortisol levels in the paroxetine group $(p=0.06)$.

Conclusion: Paroxetine has a beneficial effect on measures of insulin sensitivity and may improve glycemic control. Larger studies of longer duration are needed to verify the benefits of paroxetine in type 2 diabetes. While waiting for more conclusive evidence it seems sensible to augment standard care of type 2 diabetes with paroxetine even in patients who do not fulfil routine psychiatric criteria for initiation of antidepressant drug treatment. 


\section{Background}

Type 2 diabetes, characterised by both insulin resistance and impaired insulin secretion, is a common disease with rapidly increasing prevalence worldwide $[1,2]$. Insulin resistance is one of the primary metabolic defects, both in the metabolic syndrome and in type 2 diabetes. Therefore a main treatment target is to improve insulin sensitivity. The cornerstones of treatment are exercise and improved dietary habits. Insulin sensitivity improves with weight loss and physical activity [3]. Unfortunately, success of non-pharmacologic treatment is rare. Therefore other means to increase insulin sensitivity are urgently needed.

One possibility for pharmacological treatment of insulin resistance is the use of serotonergic agents such as the selective serotonin reuptake inhibitors (SSRIs). It has previously been shown that the SSRI fluoxetine lowers blood glucose levels in type 2 diabetics [4,5]. Fluoxetine has also been shown to promote weight loss [6], which in itself would improve insulin sensitivity. Interestingly, this effect of fluoxetine on insulin sensitivity also occurs independently of weight loss [7].

The metabolic syndrome is characterised not only by insulin resistance but also by obesity, elevated blood pressure, dyslipidemia, an increased risk for cardiovascular disease and for depression [8]. Symptoms of depression among type 2 diabetics have been shown to correlate with glycemic control although it is not clear whether this is due primarily to non-compliance with the anti-diabetic medication or to depression [9]. Therefore, in order to reduce the risk for cardiovascular diseases associated with the metabolic syndrome and type 2 diabetes, it is important to treat not only hyperglycemia in type 2 diabetes but also all other risk factors accompanying the disease. It is of interest to see whether antidepressant drugs could be beneficial for diabetics with regard to metabolism as well as mental health.

The aim of our investigator-initiated study was to assess whether the SSRI paroxetine has beneficial effects on the overall metabolic control in type 2 diabetics, in addition to possible beneficial effects on mental health.

\section{Methods}

Mildly depressed type 2 diabetes patients were invited to participate in this 10 -week trial. All subjects received standard diabetes treatment by their primary care physicians prior to and during the trial. Postmenopausal women over 50 years of age, who had been diagnosed with type 2 diabetes at least a year prior to study entry were eligible for the study. They had to be on stable antidiabetic medication for at least three months before entering the study.
All subjects were interviewed by the same investigator (M.P.) and were evaluated using two clinician-rated evaluation scales, Hamilton's Anxiety Scale (HAM-A) [10] and Montgomery-Åsberg's Depression Rating Scale (MADRS) [11], and two patient-rated scales, Beck's Depression Inventory [12] (BDI) and the RAND-36 for assessment of quality of life [13].

Inclusion criteria were unsatisfactory glycemic control, defined as $\mathrm{GHbA}_{1 \mathrm{c}} \geq 6.5 \%$ or fasting blood glucose $\geq 7.0$ $\mathrm{mmol} / \mathrm{l}$, and mild depression, defined as a score between 2.5 and 12 on the MADRS, i.e. they had a mild to moderate but not a severe depression requiring immediate treatment.

Subjects with major complications due to diabetes (e.g. major cardiovascular disease, renal insufficiency, blindness, amputations) were excluded. Furthermore, subjects were excluded if they had glaucoma [14] and if they were using warfarin [15] because of possible adverse effects of paroxetine in these conditions. Patients who used any kind of antidepressants were excluded.

22 subjects were interviewed in person and 7 of these did not meet the inclusion criteria for the study. Therefore, 15 subjects were randomly assigned to take either placebo ( $\mathrm{n}$ $=8)$ or $20 \mathrm{mg}$ paroxetine $(\mathrm{n}=7)$ once a day in a singleblind fashion. The randomisation was computerised and concealed to both patient, investigators, and treating physicians until inclusion and informed consent was established. The allocation remained concealed to the patient, treating physician and laboratory staff throughout the trial. The investigator did not take part in the clinical treatment of the study subjects.

At baseline and after 10 weeks the mental status of the participants was evaluated using MADRS, BDI, RAND-36, and HAM-A. At the same timepoints blood samples were drawn for the following analyses: blood glucose, $\mathrm{GHbA}_{1 \mathrm{c}^{\prime}}$ serum cholesterol, serum HDL-cholesterol, serum triglycerides, free fatty acids (FFA), serum cortisol, sex hormone binding globulin (SHBG), and serum leptin. LDL cholesterol was calculated using the Friedewald formula. Body mass index $\left(\mathrm{kg} / \mathrm{m}^{2}\right)$ was calculated using body weight measured to the nearest $0,5 \mathrm{~kg}$ and height to the nearest $\mathrm{cm}$. Basal metabolic rate $(\mathrm{kcal} / 24 \mathrm{~h})$ was measured using indirect calorimetry [16]. All measurements were made after an overnight fast (at least $8 \mathrm{~h}$ fasting).

At baseline, at four week intervals, and at endpoint adverse events were registered and the following safety blood tests were taken: blood count, serum sodium, serum potassium and liver enzymes. Subjects were to be removed from the study if any safety tests showed 


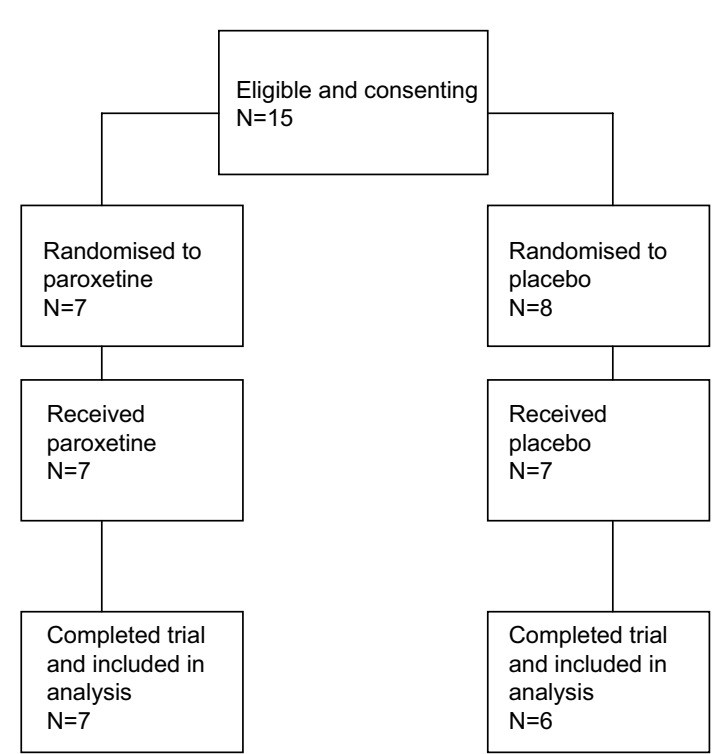

Figure I

Flow chart of trial participants.

abnormal results. Compliance with the medication was ensured by pill counting.

The primary outcome measures were global improvement, defined as at least $20 \%$ increase in the total score of quality of life, and metabolic improvement, defined as a decrease in $\mathrm{GHbA}_{1 \mathrm{c}}$ of at least $10 \%$.

The study was approved by the Ethics Committee of Helsinki University Central Hospital. All participants signed an informed consent form.

Subjects who dropped out of the trial after more than two weeks of participation were included in the analysis by last observation carried forward technique. All analyses were made with the SPSS 11.0 software. Differences between groups in mean changes from baseline were analysed with the non-parametric two-tailed Mann-Whitney U-test.

\section{Results}

Fifteen women entered randomisation; seven were allocated to paroxetine and eight to placebo. One patient withdrew her consent before starting medication and one dropped out due to gastroenteritis after one week in the trial. Both were allocated to the placebo group. All others completed the 10 week trial (Figure 1).
Baseline characteristics of those women who entered and completed the study are given in Table 1 . Baseline features were similar in the two treatment groups. The subjects were in general obese with a non-optimal glycemic control having mean fasting blood glucose above $8 \mathrm{mmol} / \mathrm{l}$. All patients were using oral antidiabetic drugs except for one diet treated individual in the placebo group. Three of the patients in the paroxetine group were using insulin and oral antidiabetic medication combined, but none of the controls. Depression and anxiety scores indicated presence of psychiatric distress among all study participants.

After ten weeks we found that the mean decrease of the GHbA1c value in the paroxetine group was $0.44 \%$-units (Table 2). There was a trend towards a more beneficial outcome in the paroxetine group, as GHbA1c in the placebo group decreased only $0.07 \%$-units $(U=9.0, p=$ $0,08)$. Fasting blood glucose improved in both groups $(1.5 \mathrm{mmol} / \mathrm{l}$ in the paroxetine group and $0.8 \mathrm{mmol} / \mathrm{l}$ in the control group, $\mathrm{U}=18.5, \mathrm{p}=0.72$ ). A beneficial change was seen in SHBG values in the paroxetine group in contrary to a decrease of SHBG in the placebo-treated group. In this respect the treatment groups differed significantly from each other $(U=3.0, p=0.01)$. Body weight and body mass index decreased slightly in both of the groups, as well as serum cholesterol and LDL cholesterol.

Improvement in overall quality of life as measured by RAND-36 did not differ between groups $(U=18.0$, $p=$ 0.67 ) (Table 3). The paroxetine-treated women evidenced a decrease of anxiety and depressive symptoms in the investigator-rated scales, but a significant difference between paroxetine- and placebo-treated participants was not reached (HAM-A $U=10.5, p=0,13$; MADRS $U=13.0$, $\mathrm{p}=0.25$ ). All participants, irrespective of group allocation, improved according to the patient-rated depression scale BDI $(U=20.0, p=0.88)$, but there was a trend for greater decrease in serum cortisol levels, a depression marker, in the paroxetine group $(U=8.0, p=0.06)$.

Seven of the 14 patients who initiated medication reported mild adverse events; four in the paroxetine group and three in the control group. The paroxetine-treated patients reported chronic constipation $(\mathrm{n}=1)$, sweating $(\mathrm{n}=1)$, decreased appetite $(\mathrm{n}=1)$, and hand paresthesias $(\mathrm{n}=1)$. It is likely that the sweating, decreased appetite, and paresthesias were related to the paroxetine treatment. The participants in the placebo group reported sweating $(\mathrm{n}=1)$, nausea combined with headache $(\mathrm{n}=1)$, and gastroenteritis $(n=1)$. Due to her symptoms, the patient with gastroenteritis discontinued her participation in the trial. 
Table I: Baseline characteristics of mildly depressed women with type 2 diabetes who completed the trial

\begin{tabular}{|c|c|c|c|c|}
\hline & \multicolumn{2}{|c|}{ Controls $(n=6)$} & \multicolumn{2}{|c|}{ Paroxetine $(n=7)$} \\
\hline & Mean & SD & Mean & SD \\
\hline Age (years) & 62.3 & 11.5 & 61.1 & 8.6 \\
\hline Body mass index $(\mathrm{kg} / \mathrm{m} 2)$ & 30.1 & 6.3 & 31.6 & 3.0 \\
\hline \multicolumn{5}{|l|}{ Metabolic parameters } \\
\hline Fasting blood glucose (mmol/l) & 8.4 & 1.3 & 8.9 & 2.8 \\
\hline $\mathrm{HbAIc}(\%)$ & 6.9 & 0.4 & 7.5 & 0.8 \\
\hline S-cholesterol (mmol/l) & 5.5 & 1.4 & 5.8 & 1.0 \\
\hline HDL cholesterol (mmol/l) & 1.6 & 0.4 & 1.4 & 0.2 \\
\hline LDL cholesterol (mmol/l) & 3.0 & 1.2 & 3.7 & 0.9 \\
\hline S-triglycerides $(\mathrm{mmol} / \mathrm{l})$ & 2.1 & 1.1 & 1.5 & 0.7 \\
\hline Free fatty acids (mmol/l) & 0.9 & 0.4 & 1.0 & 0.2 \\
\hline Sex hormone binding globulin (nmol/l) & 74.2 & 34.3 & 38.9 & 19.5 \\
\hline S-leptin $(\mathrm{ng} / \mathrm{ml})$ & 32.2 & 14.9 & 22.9 & 15.2 \\
\hline S-cortisol (nmol/l) & 460.2 & 130.0 & 550.7 & 120.7 \\
\hline Energy expenditure (kcal/d) & 1516.7 & 167.7 & 1658.6 & 246.5 \\
\hline \multicolumn{5}{|l|}{ Mental status } \\
\hline Hamilton's Anxiety Scale & 9.3 & 3.7 & 13.7 & 4.2 \\
\hline Montgomery-Åsberg's Depression Rating Scale & 6.4 & 4.0 & 7.4 & 2.9 \\
\hline Beck's Depression Inventory & 13.0 & 9.2 & 13.7 & 7.4 \\
\hline RAND-36 & 436.8 & 182.0 & 455.6 & 142.7 \\
\hline
\end{tabular}

Table 2: Mean changes in metabolic parameters between baseline and endpoint in women treated with placebo or paroxetine

\begin{tabular}{|c|c|c|c|c|c|c|}
\hline & \multicolumn{2}{|c|}{ Placebo $(n=6)$} & \multicolumn{2}{|c|}{ Paroxetine $(n=7)$} & \multirow{2}{*}{$\begin{array}{l}95 \% \text { confidence } \\
\text { interval of difference } \\
\text { between groups }\end{array}$} & \multirow[t]{2}{*}{$\mathbf{p}^{*}$} \\
\hline & Mean & SD & Mean & SD & & \\
\hline Body weight (kg) & -0.83 & 0.98 & -0.71 & 2.29 & -2.30 to 2.06 & 0.60 \\
\hline Body mass index $(\mathrm{kg} / \mathrm{m} 2)$ & -0.31 & 0.38 & -0.26 & 0.88 & -0.88 to 0.79 & 0.51 \\
\hline Blood glucose $(\mathrm{mmol} / \mathrm{l})$ & -0.78 & 0.58 & -1.47 & 2.52 & -1.65 to 3.03 & 0.72 \\
\hline $\mathrm{HbAlc} \%$ & -0.07 & 0.33 & -0.44 & 0.37 & -0.05 to 0.80 & 0.08 \\
\hline S-cholesterol $(\mathrm{mmol} / \mathrm{l})$ & -0.37 & 0.72 & -0.16 & 0.62 & -1.05 to 0.63 & 0.47 \\
\hline HDL-cholesterol (mmol/l) & -0.07 & 0.10 & 0.01 & 0.13 & -0.22 to 0.07 & 0.28 \\
\hline LDL-cholesterol (mmol/l) & -0.38 & 0.65 & -0.31 & 0.51 & -0.80 to 0.68 & 0.57 \\
\hline S-triglycerides (mmol/l) & 0.16 & 0.28 & 0.31 & 0.77 & -0.87 to 0.58 & 0.72 \\
\hline Free fatty acids ( $\mathrm{mmol} / \mathrm{l})$ & -0.13 & 0.48 & -0.29 & 0.41 & -0.40 to 0.71 & 0.56 \\
\hline Sex hormone binding globulin (nmol/l) & -9.33 & 15.67 & 20.29 & 20.57 & -51.81 to -7.43 & 0.01 \\
\hline S-leptin $(\mathrm{ng} / \mathrm{ml})$ & -3.75 & 6.73 & -3.54 & 5.99 & -8.12 to 7.70 & 0.89 \\
\hline S-cortisol (nmol/l) & 104.83 & 151.05 & -42.29 & 133.73 & -30.17 to 324.41 & 0.06 \\
\hline Energy expenditure (kcal/d) & -33.33 & 157.69 & 28.57 & 177.05 & -266.35 to 142.54 & 0.57 \\
\hline
\end{tabular}

*Mann-Whitney U-test

\section{Discussion}

This is to our knowledge the first study where the metabolic and mental health effects of paroxetine have been simultaneously assessed in mildly depressed individuals with type 2 diabetes. Our study was unable to demonstrate a statistically significant difference in glycemic con- trol between paroxetine-treated and placebo-allocated women, but there was a trend for better control in the paroxetine group. In addition, we found a significant improvement in an indicator of insulin sensitivity, SHBG, in the treatment group when compared to the control group. 
Table 3: Mean changes between baseline and endpoint in mental health rating scales' total scores in women treated with placebo or paroxetine

\begin{tabular}{|c|c|c|c|c|c|c|}
\hline & \multicolumn{2}{|c|}{ Placebo $(n=6)$} & \multicolumn{2}{|c|}{ Paroxetine $(n=7)$} & \multirow{2}{*}{$\begin{array}{l}95 \% \text { confidence interval } \\
\text { of difference between } \\
\text { groups }\end{array}$} & \multirow[t]{2}{*}{$\mathbf{p}^{*}$} \\
\hline & Mean & SD & Mean & SD & & \\
\hline Hamilton's Anxiety Scale & -0.67 & 4.63 & -5.43 & 5.32 & -1.31 to 10.84 & 0.13 \\
\hline Montgomery-Åsberg's Rating Scale & -1.50 & 3.97 & -4.00 & 3.46 & -2.14 to 7.14 & 0.25 \\
\hline Beck's Depression Inventory & -5.83 & 6.24 & -6.57 & 5.80 & -6.71 to 8.19 & 0.88 \\
\hline RAND-36 & 129.4 & 139.4 & 60.5 & 270.6 & -194.93 to 332.63 & 0.67 \\
\hline
\end{tabular}

*Mann-Whitney U-test

The paroxetine-treated women showed improvements in investigator-rated aspects of mental health, but again statistical superiority when compared with the control group was not reached. In this short study no superiority of paroxetine regarding improvement in quality of life was detected.

An improvement in $\mathrm{GHbA}_{1 \mathrm{c}}$ was observed after only ten weeks of treatment with paroxetine. The decrease in $\mathrm{GHbA}_{1 \mathrm{c}}$ was not as big as $10 \%$ which was our a priori definition for a good primary outcome. However, the average decrease of $0.44 \%$ - units ( $6 \%$ improvement) can certainly be considered to be of importance. It is a wellknown fact that any improvement in glycemic control reduces the risk for microvascular complications [17]. We chose GHbA1c as the primary metabolic outcome measure because it is more reliable than the fasting glucose value, as it reflects the glycemic control during a $8-12$ weeks time period. Fasting glucose may incidentally vary a lot more and may also be affected by duration of fasting and an inclusion in the study effect cannot be excluded. Fasting blood glucose improved in both study groups. The mean absolute improvement was larger in the paroxetine group but statistical superiority of paroxetine was not reached. Thus, we cannot exclude the possibility that the improvement in fasting glucose in the both groups was primarily due to the inclusion in study effect.

The strength of the results increases knowing that all three women - all in the paroxetine group - who used insulin reported that they had lowered their daily doses of insulin during the trial. It is however impossible to calculate the significance of this fact because there were no insulinusers in the control group.

A low SHBG concentration is considered a risk factor for type 2 diabetes and a direct correlation between insulin sensitivity and SHBG has previously been demonstrated $[18,19]$. In other words, low levels of SHBG are indicative of insulin resistance. In the paroxetine group a superior increase in SHBG levels were observed. This increase in SHBG could be interpreted as a marker of improved insulin sensitivity, nicely fitting the finding of improved glycemic control in the paroxetine group.

The main shortcoming of this pilot study is the small sample size which is reflected in the low statistical power and precision of outcome measures. The short duration constitutes another weakness of the study. A longer duration would probably have strengthened the trends seen in this study. It is possible that changes in quality of life of chronically ill populations need a longer time span to develop than the current trial.

The relatively good glycemic control at baseline (average $\mathrm{GHbA}_{1 \mathrm{c}}$ level only $7.5 \%$ ) may not have been optimal for a demonstration of the full effect of treatment. Another potential weakness is that the study was not double-blind which may have influenced the results of the mental state scales that were assayed by interview i.e. the HAM-A and the MADRS. The authors have initiated a longer doubleblind placebo-controlled randomised study to replicate the preliminary promising findings of the current study.

\section{Conclusions}

Taken together, the results are encouraging and should be verified by other studies with a bigger sample size and longer period of treatment. If paroxetine has a beneficial effect on glucose and insulin metabolism in type 2 diabetics as well as on quality of life and mental wellbeing it could well be considered a drug of choice when treating type 2 diabetics for depression. An augmentation of standard diabetes care with SSRIs may be sensible even in depressed patients who do not fulfil routine psychiatric criteria for initiation of antidepressant drug treatment.

\section{Competing interests}

None declared. 


\section{Authors contributions}

KW and JE designed the study. MP carried out the interviews and performed outcome assessment. All authors participated in writing the report. All authors read and approved the final manuscript.

\section{References}

I. Harris MI, Flegal KM, Cowie CC, Eberhardt MS, Goldstein DE, Little RR, Wiedmeyer HM and Byrd-Holt DD: Prevalence of diabetes, impaired fasting glucose, and impaired glucose tolerance in US adults: the Third National Health and Nutrition Examination Survey, 1988-94 Diabetes Care 1998, 21:5। 8-524.

2. Nelson RG, Everhart JE, Knowler WC and Bennett PH: Incidence, prevalence, and risk factors for non-insulin dependent diabetes mellitus Primary Care 1988, 15:227-250.

3. Golay A, Felber JP, Dusmet M, Gomez F, Curchod B and Jequier E: Effect of weight loss on glucose disposal in obese and obese diabetic patients Int J Obes 1985, 9:181-190.

4. O'Kane M, Wiles PG and Wales JK: Fluoxetine in the treatment of obese type 2 diabetic patients Diabetic Med 1994, I I: I05-I I0.

5. Gray DS, Fujioka K, Devine W and Bray GA: A randomized double-blind clinical trial of fluoxetine in obese diabetics Int J Obes Relat Metab Disord 1992, 16(Suppl 4):S67-S72.

6. Levine LR, Enas GG, Thompson WL, Byyny RL, Dauer AD, Kirby RW, Kreindler TG, Levy B, Lucas CP and Mcllwain HH: Use of fluoxetine, a selective serotonin-uptake inhibitor, in the treatment of obesity: a dose-response study Int J Obes 1989, 13:635-645.

7. Maheux P, Ducros F, Bourque J, Garon J and Chiasson JL: Fluoxetine improves insulin sensitivity in obese patients with non-insulin-dependent diabetes mellitus independently of weight loss Int J Obes Relat Metab Disord 1997, 21:97-102.

8. Gavard JA, Lustman PJ and Clouse RE: Prevalence of depression in adults with diabetes: an epidemiological evaluation Diabetes Care 1993, 16:1167-1178.

9. Goodnick PJ, Kumar A, Henry JH, Buki VM and Goldberg RB: Sertraline in coexisting major depression and diabetes mellitus Psychopharmacol Bull 1997, 33:26I-264.

10. Gjerris A, Bech P, Bojholm S and Rafaelsen OJ: The Hamilton Anxiety Scale J Affect Dis 1983, 5:163-170.

II. Montgomery SA and Asberg M: A new depression scale designed to be sensitive to change Brit J Psychiatry 1979, 134:322-389.

12. Beck AT, Ward CH, Mendelson M, Mock J and Erbaugh J: An inventory for measuring depression Arch Gen Psychiatry I96I, 4:56I$57 I$.

13. Hays RD, Sherbourne CD and Mazel R: The RAND 36-item Health Survey I.0 Health Economics 1993, 2:217-277.

14. Eke T and Bates AK: Acute angle closure glaucoma associated with paroxetine $B M]$ I997, 3 I 4(709 I): 1387.

15. Duncan D, Sayal K, McConnel H and Taylor D: Antidepressant interactions with warfarin Int Clin Psychopharmacology 1998, 1 3:87-94.

16. Meriläinen PT: Metabolic monitor Int J Clin Monit Comput 1987, 4:167-I77.

17. Turner RC: The U.K. Prospective Diabetes Study. A review Diabetes Care 1998, 21 (Suppl 4):C35-C38.

18. Abate N, Haffner SM, Garg A, Peshock RM and Grundy SM: Sex steroid hormones, upper body obesity, and insulin resistance J Clin Endocrinol Metab 2002, 10:4522-4527.

19. Cibula D, Skrha J, Hill M, Fanta M, Haakova L, Vrblkova J and Zivny J: Prediction of insulin sensitivity in nonobese women with polycystic ovary syndrome J Clin Endocrinol Metab 2002, I 2:582I5825.

\section{Pre-publication history}

The pre-publication history for this paper can be accessed here:

http://www.biomedcentral.com/1471-2296/4/7/prepub
Publish with Bio Med Central and every scientist can read your work free of charge

"BioMed Central will be the most significant development for disseminating the results of biomedical research in our lifetime. "

Sir Paul Nurse, Cancer Research UK

Your research papers will be:

- available free of charge to the entire biomedical community

- peer reviewed and published immediately upon acceptance

- cited in PubMed and archived on PubMed Central

- yours - you keep the copyright
BioMedcentral 